Pedagogía y Saberes n. ${ }^{\circ} 52$

Universidad Pedagógica Nacional

Facultad de Educación. 2020. pp. 53-66

\title{
Prácticas formativas de la familia: la configuración de la mujer formadora*
}

\section{Artículo de investigación}

Formative Practices of the Family: The Configuration of the Woman as Educator

Práticas formativas da família: a configuração da mulher formadora

Javier Sáenz Obregón**

Manuela Salcedo***

Para citar este artículo:

Sáenz, J. y Salcedo, M. (2020). Prácticas formativas de la familia: la configuración de la mujer formadora. Pedagogía y Saberes, 52, 53-66. DoI: https://doi.org/10.17227/pys.num52-11022

* Artículo resultado de investigación en curso, desarrollada en el Centro de Estudios Sociales de la Universidad Nacional de Colombia y financiado por Colciencias.

** Profesor titular del Departamento de Sociología e investigador Centro de Estudios Sociales, Universidad Nacional de Colombia. Ph.D. Historia y Filosofía de la Educación del Institute of Education, University College London. Investigador del Grupo Gobierno, subjetividades y prácticas de sí y del Grupo Historia de la Práctica Pedagógica (GHPP).

Correo electrónico: jsaenzo@unal.edu.co

Código oRCID: http://orcid.org/0000-0001-6129-7811

*** Estudiante Maestría en Educación, Universidad Nacional de Colombia. Investigadora del Grupo Gobierno, subjetividades y prácticas de sí.

Correo electrónico: masalcedoru@unal.edu.co Código oRCID: http://orcid.org/0000-0002-5771-4122 


\title{
Resumen
}

Este artículo es resultado de una investigación en curso. Presenta uno de los resultados del caso de la formación de la familia, del proyecto de investigación "Prácticas formativas por fuera de la escuela". Expone el abordaje del proyecto a partir de su uso de los conceptos de formación (Bildung), gobierno, contraconductas y prácticas de sí, así como de sus preguntas en torno a la dimensión conceptual, las características y los efectos de las prácticas formativas. A partir de un examen detallado de textos de formación de la familia (tratados, manuales y una novela ejemplarizante) entre el siglo xv y el xx en Europa Central y Colombia, se describen y analizan tres acontecimientos en la configuración de la mujer como formadora: i) la valoración católica de su naturaleza como moral e intelectualmente débil; ii) su configuración como principal responsable de la formación moral de sus hijos; iii) su valoración como moralmente superior al hombre y, por tanto, como responsable de la formación moral de su esposo. El texto problematiza y esboza algunas ideas para comprender dos asuntos paradójicos que emergen del examen de estos acontecimientos: si es concebida como moralmente débil, ¿por qué se le asigna el papel de formadora moral de sus hijos?, y posteriormente, si es valorada como moralmente superior al hombre y como su formadora moral, ¿por qué sigue ocupando un lugar subordinado a él?

\section{Palabras clave}

moral; Pestalozzi; Vives; gobierno; amor materno; formación; familia; madres

\begin{abstract}
This article is the result of an on-going research project. It presents one of the results of the case-study on the formation of the family, undertaken as part of the research project on Out of school formative practices. It presents the approach of the project, based on the use of the concepts of formation (Bildung), government, counter-conducts and practices of the self; and its central questions regarding the conceptual dimension, characteristics and effects of these practices. Based on a detailed examination of texts directed to the formation of the family (treatises, manuals and an exemplary novel) between the xv and the xx century in central Europe and Colombia, the article describes and analyses three events in the configuration of mothers as educators in the family (i) the catholic valuation of their nature as morally and intellectually weak, (ii) their configuration as responsible for the moral formation of their sons and daughters, (iii) their valuation as morally superior to men and therefore as responsible for the moral education of their husbands. The text problematizes two paradoxes and presents some ideas in order to understand them: being conceived as morally weak why are mothers assigned the role of forming morally their children?, and later, being conceived as morally superior to men, why do they continue having a subordinate position vis a vis their husbands?
\end{abstract}

\section{Key words}

morality; Pestalozzi; Vives; government; maternal love; formation; family; mothers

\section{Resumo}

0 artigo é o resultado de uma pesquisa em desenvolvimento. Apresenta um dos resultados do caso da formação da família, do projeto de investigação Práticas formativas fora da escola. Apresenta uma abordagem do projeto a partir do uso dos conceitos formação (Bildung), governo, contracondutas e práticas de si, assim como de suas perguntas ao redor da dimensão conceitual, as características e os efeitos das práticas formativas. Sob um exame detalhado de textos acerca da formação da família (tratados, manuais e uma novela exemplarizante) entre o século xv e o xx na Europa central e Colômbia, descrevem-se e analisam-se três acontecimentos na configuração da mulher como formadora: (i) a valoração católica da sua natureza como moral e intelectualmente débil, (ii) sua configuração como principal responsável da formação moral de suas filhas e filhos, (iii) sua valoração como moralmente superior ao homem e, por tanto, como responsável da formação moral de seu esposo. 0 texto problematiza e esboça algumas ideias com o propósito de compreender dos assuntos paradoxais que emergem do exame destes acontecimentos: sendo concebida como moralmente fraca por que lhe é assignado o papel de formadora moral de seus filhos? e, posteriormente, sendo valorada como moralmente superior ao homem e como sua formadora moral, por que segue ocupando um lugar subordinado a ele?

\section{Palavras-chave}

moral; Pestalozzi; Vives; governo; amor materno; formação; família; mães 


\section{Introducción}

$\mathrm{E}$ ste escrito recoge algunos resultados de la formación de la familia del proyecto de investigación "Prácticas formativas por fuera de la escuela", ${ }^{1}$ uno de los doce casos que examina este proyecto. Aquí se analizan algunos acontecimientos históricos en estas prácticas por medio del estudio de tratados, manuales y una novela ejemplarizante de Europa Central y Colombia, entre los siglos XV y XX.

Desde mediados del siglo pasado, estas prácticas formativas extraescolares se han potenciado y multiplicado, tanto a nivel nacional como internacional, de la mano de la emergencia de nuevos discursos y prácticas sobre el desarrollo humano, la educación popular y comunitaria, la educación permanente, el autoaprendizaje, las sociedades de conocimiento, las ciudades educativas y los nuevos medios de tecnología e información, entre otros. Este proceso ha pedagogizado y escolarizado la vida, y supone una vocación formativa estrechamente ligada a procesos de gobierno y de formación para vivir bien, que fue posible por el despliegue de múltiples actores internacionales y del país, en torno a la formación extraescolar: la Iglesia católica, el Estado, las instituciones caritativas, filantrópicas y médicas; la policía, las élites y los intelectuales, los organismos no gubernamentales y multilaterales, las organizaciones y movimientos sociales, las tecnologías y los medios masivos de comunicación (radio, televisión, prensa escrita, internet), así como la misma escuela que en diversos periodos desplegó y sigue desplegando prácticas de formación extraescolares, dirigidas en especial a las familias de los estudiantes.

La pedagogización de la vida familiar, relativamente masificada y con visos de escolarización, ha constituido una estrategia central de las élites, el Estado y la Iglesia, desde la invención de la escuela en el siglo XV y contribuyó a configurar la familia cristiana, civilizada y burguesa moderna: a encerrar a sus miembros en el hogar, a diferenciar los roles y

1 Proyecto auspiciado por Colciencias y desarrollado por el grupo de investigación "Gobierno, subjetividades y prácticas de sí", del Centro de Estudios Sociales de la Universidad Nacional de Colombia, y el grupo "Diverser" de la Facultad de Educación de la Universidad de Antioquia, con la asesoría de Gabriela Diker, rectora de la Universidad Nacional General Sarmiento de la Argentina. Además de lo que se examina en este artículo, el proyecto incluye los siguientes tres casos de prácticas formativas históricas: formación política, formación para la urbanidad y de estrategias formativas de la policía; así como los siguientes ocho casos contemporáneos: de fuera de la escuela en la escuela, en torno a la paz, medioambientales, de salud, de los parques-biblioteca de Medellín, en Facebook, en torno al arte y la formación para amar. espacios de los miembros de la familia (Ariès, 1987), a expulsar de los hogares a los que no eran miembros de la familia nuclear (Donzelot, 1990), y a implantar formas específicas de gobierno de los padres y las madres sobre los hijos, de los padres sobre las madres, y a que las madres gobernaran a los padres y los retuvieran en el hogar (Sáenz y Granada, 2013).

Esta pedagogización/escolarización tuvo lugar, primordialmente, por medio de manuales dirigidos a los padres y madres para la formación/gobierno de la familia, cuyos primeros ejemplos en Europa Central han sido examinados de manera general por estudiosos como Werner Sombart (1988) y Norbert Elias (1989). También constituyó una estrategia por parte del Estado y las escuelas para reformar la vida y la educación familiar, haciéndola más afín a la de las escuelas.

El significado central que le otorgamos a la familia como escenario formativo se relaciona con tres asuntos: a) la convicción que, junto con la escuela, ha constituido una de las principales líneas de fuerza en la tribu occidental de fabricación del sujeto moderno; b) la especificidad y complejidad de las formas de gobierno en este escenario, y c) la manera en que dicha formación/gobierno ha servido, como lo señala Foucault (2000), como anclaje de las prácticas de formación/gobierno en otros escenarios, en especial en las escuelas, los lugares de trabajo, las cárceles y los asilos.

\section{Abordaje}

Entendemos las prácticas formativas por fuera de la escuela en su complejidad, en primer lugar, como prácticas que históricamente han tenido un propósito instructivo: impartir normas y saberes de civilidad, virtud cristiana, alfabetización, salud, trabajo ciudadanía, medio ambiente, sexualidad, entre muchos otros asuntos. En segundo lugar, como prácticas que anudaron la instrucción a formas de gobierno específicas de individuos, grupos poblacionales y la población en general. En tercer lugar, como prácticas que actuaron como líneas de fuerza dentro de dispositivos históricos de configuración de sujetos: del sujeto moderno y contemporáneo, pero también de sujetos específicos: el sujeto campesino-indígena-afrourbano, pobre-burgués-de la élite, hombre-mujer, niños-jóvenes-adultos, normal-anormal, virtuosovicioso, vago-trabajador, civilizado-bárbaro, etc. En cuarto lugar, como prácticas a partir de las cuales se desarrolló un discurso, un saber y una mirada en torno a los grupos poblacionales sobre los que actuaron, haciéndolos inteligibles y visibles dentro 
de los regímenes de enunciabilidad y visibilidad en las que dichas prácticas se inscribieron. En quinto lugar, como prácticas que se conectaron, con mayor o menor intensidad, con otro tipo de prácticas: escolares, culturales, económicas, religiosas, políticas y sociales. Por último, como prácticas contraconductuales que apuntan a la formación de subjetividades contrahegemónicas, como es el caso de algunos de los procesos formativos de los organismos no gubernamentales y movimientos sociales en el país desde la década de 1980 .

Quisiéramos hacer, de manera esquemática, algunas precisiones sobre tres conceptos centrales del abordaje de la investigación. Primero, sobre la formación: ¿Por qué formación, y no pedagogía o educación? Como lo señala Vierhaus (2002), el concepto de formación (bildung) se puede rastrear al siglo XIV y su sentido inicial tenía tres componentes: dar o darse una forma, el desenvolvimiento de las fuerzas humanas y el efecto de la educación (Vierhaus, 2002, pp. 8-11). Lo usamos en este texto como un concepto abarcador, dentro del cual habría una pluralidad de modalidades formativas: la pedagogía, la instrucción, la enseñanza, el entrenamiento, el aprendizaje, la disciplina, el gobierno, etc. Por formar entendemos, entonces, el efecto de las prácticas en la forma-sujeto: tanto en cuanto a aquellas potencias (pensamientos, emociones, voluntad, corporalidades, imaginaciones, sentimientos, sensaciones, placeres, deseos, intereses, fantasías) que se intensifican o debilitan afectando esta forma-sujeto; como en cuanto a su forma misma: forma-individuo (encerrado en sí mismo), forma-dividuo (que se autoexperimenta como irremediablemente escindido de manera dualista) (Foucault, 1988) o formas múltiples, formas-colectivos o fuerzas informes.

Un segundo concepto que quisiéramos aclarar es el de gobierno, que entendemos en el sentido amplio en que lo definió Foucault (2006) como la conducción de las conductas. Este concepto hace posible especificar una de las modalidades formativas, característica de la formación en la familia: aquella en que la formación adquiere la forma de una estrategia relativamente estable de conducción de las conductas de los miembros de la familia. Este planteamiento tiene dos implicaciones centrales. De una parte, que los sujetos que están siendo formados ya venían actuando, ya se venían conduciendo y estaban siendo conducidos por otros; y que, por tanto, las prácticas formativas entran en un flujo, en un devenir que ya traían los sujetos. ${ }^{2}$ De otra parte, que las prácticas fabrican tanto sujetos

2 Sobre la formación como conexión con el flujo de la acción, véase Dewey (2004). como conductas, conceptos, saberes, objetos, sujetos: eso es que son productivas y no solo negativas (crean, no solo reprimen o excluyen).

Estrechamente ligado a lo anterior, están dos conceptos que también quisiéramos precisar: el de contraconductas y el de prácticas de sí, que también son centrales en nuestro proyecto. El primero se refiere a las prácticas contrahegemónicas por medio de las cuales los sujetos buscan conducirse y ser conducidos de otra forma, con otros fines, por otras razones y por otros (Foucault, 2006), y estas adquieren características múltiples que se pueden enfrentar a las formas en que los sujetos están siendo formados/gobernados, buscando derrotarlas; pueden apoderarse de ellas, usándolas o desviándolas; o pueden evadirlas, creando líneas de fuga (Sáenz, 2014). El segundo se refiere a aquellas prácticas, cada vez más frecuentes en las escuelas y en general en las prácticas formativas, que se refieren a las acciones conscientes de los sujetos sobre sí mismos para transformarse o fijar su identidad (Foucault, 1999a, 1999b). Prácticas que, tanto en su versión más institucionalmente cristiana de autogobierno virtuoso, como en su versión de autogobierno para la cortesía y la civilidad, se introdujeron decididamente en la pedagogía escolar y en los manuales y tratados dirigidos a la formación de la familia desde el siglo XV.

El proyecto privilegia el análisis de las modalidades específicas de formar, y aborda las siguientes preguntas: ¿Cómo han contribuido estas prácticas al gobierno (incluyendo el autogobierno) de los individuos y la población, conduciendo sus conductas? ¿Qué efectos han generado estas prácticas en la forma/sujeto y sus potencias? ¿En qué medida emulan o se diferencian de las prácticas pedagógicas escolares (pedagogización) y de encierro, distribución espacial, temporal y de los cuerpos de la escuela clásica (escolarización)? ¿Cuál es la potencia de estas prácticas en términos de sus efectos éticos, sociales, políticos, culturales y económicos?

En los estudios de caso se utiliza un abordaje metodológico de análisis de discursos y de trabajo etnográfico de campo, a partir de una rejilla de análisis para dar cuenta de la dimensión conceptual de las prácticas, sus características y sus efectos. El abordaje metodológico para el examen de las prácticas y saberes retoma las formalizaciones de dos grupos de investigación que hacen parte de este proyecto, basadas en los planteamientos de Foucault (1975, 1977, 1978, 1985, 1988, 1999a): la propuesta inicial para examinar las prácticas pedagógicas de Olga Lucía Zuluaga (1987) y del Grupo de Historia de la Práctica Pedagógica, así como sus ampliaciones, 
llevadas a cabo por el grupo "Gobierno, subjetividades y prácticas de sí”, en su investigación sobre prácticas de sí históricas y contemporáneas (Sáenz, 2014). Dicho abordaje se dirige a i) problematizar la forma específica de las prácticas en términos de sus estrategias o métodos, así como sus fines y las poblaciones a las que se dirigen; ii) examinar los conocimientos y saberes en los que se sustentan; iii) analizar las concepciones centrales en las que se fundamentan, como: formación, sujeto, enseñante, estudiante, aprendizaje, conocimiento/saber, moral, sociedad, política, economía; iv) visibilizar su grado de institucionalización y las relaciones que establecen con otras prácticas y procesos más generales: prácticas económicas, sociales culturales, políticas; v) comprender sus continuidades y discontinuidades históricas.

La estrategia de diseño de los instrumentos, además de la sistematización y análisis puntual de la información, tanto la proveniente de análisis documentales como del trabajo etnográfico, ha estado orientada por una grilla de análisis que formula preguntas en tres sentidos: la identificación e interpretación de los conceptos (sujetos de enunciación, sujetos que son objetivo de las prácticas, formas de enunciación, saberes, fines); la caracterización de las prácticas (definición del sujeto a formar, formas de aprendizaje, relaciones entre aprendiz y formador, temas de formación y potencias del sujeto que se busca afectar); y finalmente, los efectos de estas prácticas sobre los individuos y los grupos poblacionales (individualización, infantilización, potenciación/ debilitamiento del sujeto, producción de saberes, generación o conexión con procesos sociales, culturales, éticos, políticos o económicos).

\section{La configuración de la mujer formadora}

Entre los resultados del proyecto "Prácticas formativas por fuera de la escuela”, en este artículo nos concentramos en el lugar de la mujer como formadora de la familia en algunos tratados de formación y una novela ejemplarizante en Europa Central y Colombia entre los siglos XV y xx. Examinamos en primer lugar el giro hacia la desconfianza moral en la mujer que se puede constatar en el paso del tratado renacentista sobre la familia de León Battista Alberti, del siglo xv, y los tratados católicos de Juan Luis Vives y Fenelón, de los siglos XVI y XVII, giro que estuvo acompañado por dudas acerca de su idoneidad para formar a sus hijos. En segundo lugar, analizamos otro giro de finales del siglo XVIII e inicios del XIX de transformación en la valoración moral de la mujer, transformación que aparece en la novela Leonardo y Gertrudis, y varios escritos dirigidos a las madres de familia, de Johann Heinrich Pestalozzi, y que recurre en varios tratados y manuales colombianos del siglo XIX. De la mano de este segundo acontecimiento, la nueva y positiva valoración de la mujer - que en algunos textos lleva a que se le considere moralmente superior al hombre-, esta se configura como el sujeto central de la formación de la familia: ya no solo como la principal formadora de la moral de sus hijos, sino como quien moldea espacial, temporal, estética y virtuosamente a la familia, y como formadora moral de su esposo a quien debe salvar de los peligros del mundo, conduciéndolo a que se refugie en el hogar.

\section{La desconfianza católica hacia la mujer}

En el que es quizás el primer tratado moderno para la formación de la familia - El libro de la familia, de 1437, del cortesano, intelectual y arquitecto florentino Leon Battista Alberti (2004)—, encontramos tanto una mirada sobre la naturaleza de la mujer y su papel como formadora muy diferente a la de los manuales y tratados que le sucedieron en los siguientes cuatro siglos, como concepciones y prescripciones que recurrirían en dichos textos. Lo primero que habría que destacar es que con pocas excepciones - a diferencia de los textos de los siguientes siglos en que el papel formador del padre hacia los hijos, más allá de las enseñanzas académicas, es casi inexistente- en El libro de la familia, el padre cumple un papel central: debe estar atento para descubrir las inclinaciones de sus hijos hacia distintos oficios, debe poner a prueba la potencia mental de estos; debe formarlos en la virtud por medio de su ejemplo, de instrucciones verbales y por medio del castigo físico. Como en escritos posteriores, Alberti prescribe que la esposa se haga cargo del gobierno económico del hogar.

Sin la misma sevicia que en los textos católicos posteriores, los personajes del diálogo en el documento de Alberti señalan solo un par de debilidades de la mujer, así Giannozzo plantea: "Las mujeres, de otra parte, son casi todas tímidas por naturaleza, blandas, lentas" (Alberti 2004, p. 207), mientras que tanto él como Leonardo consideran que no son muy buenas guardando secretos. Aunque el texto dibuja una relación entre esposos mucho menos jerárquica y cruel de la que prescriben los textos posteriores, relación en la cual, por ejemplo, Giannozzo recuerda haberle dicho a su esposa: "Si ves alguna falta en mí, te agradecería hacérmelo saber" (Alberti 2004, 
p. 211) y se jacta de nunca haberse enfurecido con ella; es evidente que se concibe al esposo como cabeza de la familia y se considera poco sabio que el marido se "subordine de forma abierta y abyecta" a ella (p. 216).

Un poco menos de un siglo más tarde del texto de Alberti, en los dos tratados prescriptivos del intelectual y pedagogo Juan Luis Vives sobre la formación de la familia - Instrucción de la mujer cristiana (1999), de 1523, y Los deberes del marido (1994), de 1529se constata, como ya dijimos, un giro radical en cuanto a la valoración de la naturaleza femenina. Giro atribuible al fundamento moral inequívoco del texto en la estrecha moral del cristianismo institucional, a diferencia del escrito de Alberti que estaba basado en la ética de filósofos griegos y helenistas. ${ }^{3}$

Vives (1999) plantea a la mujer como naturalmente más inclinada a las pasiones que el hombre: "[...] está averiguado que naturalmente amamos mucho aquellos con quienes desde niños hablamos y jugamos. Este amor puede más en la mujer porque ella naturalmente es más inclinada a cosas de placer que no el varón” (p. 41). Y la considera también más susceptible al pecado: "Cuan poderosa guerra le hacen a la mujer tres crudelísimas fieras: Soberbia, Ira y Envidia" (p. 126). La imagen que presenta de la mujer es poco menos que apocalíptica:

\begin{abstract}
Nunca vi cosa tan desaforada como es ver una demasiada ira y crueldad en una mujer, porque hallaréis algunas tan sobresalidas que con aquel su aceleramiento y encendida rabia con fuego de alquitrán, y pondrían fuego en el mundo y lo abrasarían todo, solo que saliesen con la suya y se viesen satisfechas y vengadas. (p. 126)
\end{abstract}

Además, la considera menos capaz en términos intelectuales: "[...] el pensamiento de la mujer no es muy firme; móvil es y ligero y en poco espacio de tiempo corre mucha tierra y a veces mala y llena de cien mil arriscos mortales" (Vives, 1999, p. 44). En la misma línea, Fenelón - teólogo católico quien sería más tarde arzobispo-, en su tratado de 1688, recomienda que hay que hacerle comprender a las mujeres que "son incapaces de profundizar en las dificultades del derecho" (p. 116). Casi dos siglos después, en Ensayo sobre los deberes de los casados para los ciudadanos de la Nueva Granada, Soledad Acosta (1845) también duda del rigor del pensamiento de las mujeres: "Las mujeres por lo común

3 Vives, como Alberti, cita a múltiples filósofos griegos y romanos, pero establece un estrecho filtro por el que solo pasan enunciados aceptables para el dogma eclesiástico. aman sus opiniones por debilidad y sin tomarse el trabajo de escaminar sus fundamentos [...]. De aquí nace su encaprichameinto y su entusiasmo por seguir opiniones perjudiciales o ridículas" (p. 6). ${ }^{4}$

El listado de las debilidades y vicios que, según Vives (1994), le serían naturales por ser mujer no se agota aquí: tendría "un temperamento medroso, avaro, apocado" (p. 170), "cuando piensa a solas piensa mal" (p. 171), "el sexo femenino es débil por su propio natural, e indefenso [...], su cuerpo está afectado e infectado por un semillero de enfermedades, y de ahí sus cambios de humor y las frecuentes explosiones de su alma" (p. 196).

El discurso de Vives (1999), como sería recurrente en los siguientes siglos, pasa por una evidente desconfianza hacia las mujeres desde la infancia, por lo que considera que deben ser formadas y gobernadas de manera más puntillosa y estricta que los varones - - [...] porque salió de su costado, es más inclinable y flaca, y menos aparejada para sostener las flaquezas que acarrea la vida humana, a cuya causa ha menester defensa y amparo" (p. 220)-y estar siempre, durante toda su vida, bajo la guía y vigilancia de un hombre:

Diciendo yo de los hijos que deben ser refrenados y
tenidos debajo de castigo, no dejo de las hijas en el
tintero, a quien (según nos aconseja el sabio) nunca
les debemos quitar el azote de encima, porque los
hombres con la licencia nos hacemos peores, pero
las mujeres se tornan malas de todo. Porque, aun-
que nosotros nos inclinamos a los vicios comunes
a hombre y mujer, ellas son más ingeniosas y más
determinadas en ejecutarlos y esecutarlos. (Vives,
1999, pp. 338-339)

Su formación se basa en la sumisión y en la vigilancia y confinamiento, buscando que por medio de un severo gobierno de sí misma se ciña a las tres virtudes básicas de la buena cristiana: castidad, vergüenza y templanza, que serían la base de las demás deseables: honradez, obediencia, discreción, honestidad, simpleza, llaneza, modestia, cordura, gravidez, humildad, amor entrañable a su marido, afabilidad, dulzura, mansedumbre:

Pero la muchacha, puesto que no queremos tanto hacerla letrada ni bien hablada como buena y honesta, todo el cuidado de los padres debe ser desvelado en que no se le pegue cosa alguna de deshonestidad ni vicio o fealdad ni que le cunda tal cosa por ningún sentido. (Vives, 1999, pp. 38-39)

4 Aquí y en otras citas hemos mantenido la ortografía original de los textos. 
Pero es más que sumisión, la esposa debe autosacrificarse y sacrificarlo todo por su esposo: "Si la esposa ama al marido, él es para ella el padre, la madre y los hermanos, sus únicos recursos y todo lo que ella puede desear" (Vives, 1994, pp. 128-129). Solo cuando tiene una edad avanzada, Vives considera justo que

[...] no sea ya más súbdita del marido, sino igual a él, porque aquellos arrebatos y aquellos trastornos propios del ánimo excitado, que debían ser reprimidos por la autoridad casi regia del marido [...] están ya apaciguados por los años y la costumbre. (p. 220)

\section{La mujer como formadora moral de los hijos}

Pero aparece aquí la gran paradoja que se puede rastrear también en textos posteriores: si la mujer es tan débil moral e intelectualmente: ¿Por qué se le confía lo que desde el siglo xvi los manuales y tratados comienzan a considerar como una de las tareas más valiosas de la vida: formar a los niños y posteriormente a los jóvenes? Sobre lo primero, del texto de Vives - que en esto configura una clara discontinuidad con el de Alberti- queda la imagen que la formación moral de los hijos es tarea casi que exclusiva de las madres; así, en relación con las hijas, Vives (1999) advierte: "No pierda [...] la madre cuidado de tenerla de continuo debajo de las alas de la doctrina y crianza" (p. 56) y señala las modalidades de esta formación: "Aprenderá la hija por ejemplo de su madre, además de los avisos, consejos y amonestaciones que la misma le diere" (p. 48). Las pocas ocasiones en que aparece el padre como formador es en relación con la formación intelectual tanto de los hijos ${ }^{5}$ como de la esposa, función que justifican los textos a partir de la supuesta inferioridad mental de las mujeres, y además explicable por su poca instrucción académica al no acceder a la escuela o la universidad. ${ }^{6}$

Sobre la importancia de la formación de la madre a sus hijos en la familia, en Los deberes del marido, Vives (1994) duda que todo lo que hace el hombre fuera del hogar pueda "compararse con la educación de los hijos" (p. 7); y advierte que la maldad o bondad de los hijos depende en gran medida de la formación que les imparta la madre. En un giro dramatúrgico

5 Cabe aclarar que en los textos de Vives, como en algunos de los posteriores que también se dirigen a familias burguesas o de la élite, se recomienda contratar tutores para la formación en lectura, escritura, aritmética y dibujo de las hijas, y en algunos textos como el de Locke (2012), no se recomienda enviar a los hijos a la escuela.

6 Sobre esto, además del texto de Vives (1999), véase el de Zaldúa (1891). que de distintas formas se repetiría en textos posteriores, Vives (1999), en razón de su deber formador de los hijos, le atribuye a la mujer el destino moral del mundo:

¡Cuánto mayor cuidado debemos poner en la crianza y vida de la mujer cristiana; ¡siendo importante al vivir humano, que todo el bien y mal que en el mundo se hace se puede sin yerro decir ser por causa de las mujeres! (p. 37)

Es extraña esta imagen de la mujer como moralmente débil, pero a la vez como principal responsable de la virtud del mundo. De una parte, se podría argumentar que es un indicio de una nueva valoración positiva de la mujer y explicable por la importancia central que se le otorga a los cuidados y formación de la infancia desde el siglo Xv; pero de otra, también se puede ver como enunciado de la eterna culpabilidad de la mujer para el cristianismo institucional, desde Eva y la manzana. "Como la mujer sea a natura animal enfermo y su juicio no sea de todas partes seguro y pueda ser muy ligeramente engañado, según mostró nuestra madre Eva" (Vives, 1999, p. 58).

En línea con la segunda idea, sin que estemos negando la primera, el teólogo católico Fenelón, en su tratado de 1688, La educación de las niñas, llega hasta culpabilizar a las mujeres por su deseo de agradar, que asocia a la vanidad, convirtiéndole en un veneno para los hombres:

Este ciego deseo de agradar ¿puede convenir un alma cristiana, que debe considerar como una idolatría todo lo que desvíe el amor del Creador del aprecio de los hombres? Pero cuando se trata de agradar, ¿qué se pretende? ¿No es excitar las pasiones de los hombres? [...] ¿No se debe sentirse [sic] responsable de todas sus consecuencias? ¿No van siempre demasiado lejos a poco que se le encienda? ¿Preparáis un veneno sutil y mortal, lo vertéis sobre todos los espectadores y os creéis inocentes? (Fenelón, 1999, p. 102)

En Fenelón y los textos posteriores, se va dando por sentado que la formación de la familia y los hijos en el hogar es deber fundamental de la madre, así Fenelón (1999) plantea como deberes de la madre:

La mujer está encargada de la educación de sus hijos: de los varones, hasta cierta edad; ${ }^{7}$ de las muchachas, hasta que se casan o se hacen religiosas; de la conducta de los criados, de sus costumbres, de sus servicios; del detalle de los gastos, de los medios de hacerlo todo con economía y honradamente. (p. 105)

7 Edad en que la que, en las familias burguesas, su formación pasa a manos de un tutor o ingresan a la escuela. 
Se trata no solo de que la mujer forme a sus hijos, sino que le da forma a la familia, en tanto lo aconsejado por Alberti sobre su gobierno económico del hogar, recurre y se amplía y complejiza en el tiempo. En su texto de 1869 sobre economía doméstica, la escritora colombiana Josefa Acevedo de Gómez (1869) es explícita sobre la función de gobierno y formación de la madre: “[...] escribo para las mujeres, y especialmente para aquellas que no tienen una inmensa fortuna, pero sí una casa que gobernar y una familia que educar" (p. 5). Un gobierno/formación sobre todos los miembros de la familia que es en buena medida indirecto, pues se da a través del orden, el establecimiento de horarios estrictos y la gestión material del hogar: la administración de muebles, provisiones y dinero.

\section{La superioridad moral de la mujer y su papel central como formadora}

En los textos analizados hemos constatado un giro en cuanto a la valoración de la mujer y su papel formador, a finales del siglo XVIII e inicios del XIX, a partir del cual la mujer entra a ser concebida como moralmente superior al hombre. Esto legitima aún más su papel como formadora moral de los hijos y gobernante de la economía del hogar, pero amplía también su esfera formativa. La mujer entra a ser responsable de la formación moral de su esposo, para lo cual los textos prescriben un conjunto de astucias para encerrarlo en el hogar y -en el caso de los escritos de Pestalozzi-se le asigna también la formación intelectual de sus hijos en los primeros años. En el manual del colombiano Manuel María Zaldúa de 1891, Máximas y preceptos de moral, virtud y urbanidad para instrucción y provecho de mis adoradas hijas, aparece una de las declaraciones más inequívocas y completas de este giro cuyos primeros rastros encontramos en textos europeos de inicios de siglo:

La mujer encierra en su ser todo lo que hay de más bello e interesante en la naturaleza humana; y esencialmente dispuesta a la virtud, por su conformación física y moral, y por la vida apacible que lleva, en su corazón encuentran digna morada las más eminentes cualidades sociales. (p. 29)

Por esta nueva concepción de la predisposición de la mujer a la virtud, se le comienza a asignar el papel de formadora moral del esposo, como lo plantea de manera inequívoca el tratado francés de 1890 que circuló en Colombia: Educación de las madres de familia o la civilización del género humano por medio de las mujeres: "[...] en lugar de instruir a la mujer por medio del marido, debemos regenerar al marido por medio de la mujer" (Martin, 1890, p. 45). En el texto Pedagogía doméstica, de 1914, del pedagogo colombiano Martín Restrepo Mejía, el papel de consejero que en los textos hasta el siglo XVII correspondía al esposo, se transforma en una consejería mutua: los esposos deben advertirse, aconsejarse y dirigirse entre sí (Restrepo, 1914, p. 92). Pero en los textos desde finales del siglo XVIII, se advierte una y otra vez que los consejos de la esposa al marido deben ser dulces y amables:

Si un hombre ha contraído una amistad perniciosa, si se abandona a algún vicio, si descuida un deber importante, su mujer debe advertirle su falta y pintarle las consecuencias de ella con afectuosa dulzura como una amiga que observa, porque ama y espera la enmienda, por que se cree amada. (Acosta, 1845 , p. 69)

Del listado de debilidades morales de la mujer en los tratados de Vives se pasa al señalamiento de las del hombre quien, como sujeto a formar, debe ser conocido por la esposa. En el texto de Soledad Acosta (1845), los vicios de los hombres, especialmente en su juventud serían "la intemperancia, el orgullo, la holgazanería, el juego, la impiedad, el desprecio de los ancianos, la insensibilidad y el más desenfrenado libertinaje" (p. 20).

Las Conferencias para mujeres, del jesuita P. J. Conejos de 1920, dirigidas a las mujeres concebidas como ángeles "puestos por Dios en el mundo para la salvación de los hombres" (pp. 90-91), dan más pistas para conocer los vicios masculinos hacia los cuales debe estar atenta la esposa: "no aman la verdad que los ofende ni la virtud que les condena. La sinceridad se les hace dificultosa"; "se cansan pronto del esfuerzo generoso", "olvidan en la adversidad a quien amaron en la fortuna"; "su amor [...] suele ser efímero y poco fundado y se va poco a poco debilitando hasta que muere"; "su alma está devorada por una lepra terrible [...] Esa lepra es el egoísmo". Habiendo predispuesto la mirada hacia los vicios masculinos, el texto, a la manera que hacían los textos anteriores en relación con los niños y niñas, prescribe a la madre examinar al esposo para develar sus secretos:

Señoras, estudiad a los hombres. Mirad en ellos lo que veis y buscad lo que no veis. [...] Mirad, digo lo que veis con vuestros ojos, examinad atentamente a vuestro esposo; que nada se escape a vuestra discreta y fina observación. Pero buscad lo que no veis, lo que se oculta. Que hay a veces frentes muy tersas encubridoras de fondos muy turbios, sonrisas en el rostro y hieles en el corazón. Mirad lo que veis y penetrad lo que no veis. (Conejos, 1920, p. 92; cursivas del original) 
Pero la condición necesaria para poder conocer a su esposo y así formarlo moralmente es que la esposa logre que este pase el mayor tiempo posible en el hogar: se trata de un tema recurrente en los textos desde inicios del siglo xIX hasta la primera mitad del siglo xx; y los textos traen recomendaciones precisas sobre cómo lograrlo: haciendo del hogar algo acogedor, ordenado, limpio y entretenido. Es una competencia declarada entre la esposa y los cada vez más intensos y sofisticados placeres de la vida por fuera del hogar, en especial en las ciudades; placeres predeciblemente tachados como inmorales y peligrosos. En esta competencia, la mujer debe leer sobre asuntos de actualidad para mantener conversaciones de interés para el esposo; debe expresar de manera visible y entusiasta su afecto y su cariño; debe arreglarse y hacerse atractiva. En el texto Pedagogía doméstica, del pedagogo colombiano Martín Restrepo Mejía (1914), se puede ver con claridad esta estrategia explícita de encierro del marido por parte de la esposa: tiene que embellecer el hogar para que el marido llegue a él "radiante de gozo y sin querer ir con sus compañeros a la taberna" (p. 81); debe "procurar parecerle siempre hermosa y simpática", para que "os pueda considerar siempre como el más bello adorno de la casa"; de esta forma, logrará que el esposo no se extravíe, y que ella pueda así ponerle "las riendas dulcísimas del alma" (p. 98). Además del embellecimiento propio y del hogar, la mujer debe embellecer su espíritu, "por medio de lecturas instructivas y serias meditaciones", para así hacerle al esposo "más grata la permanencia en el hogar que en la calle, más apetecible vuestra compañía que la de los amigos" (p. 99).

Los primeros textos que encontramos donde se plasma de manera más decidida este giro en la valoración moral de la mujer y de su papel formador, son los del pedagogo suizo Johann Heinrich Pestalozzi (1916), tanto en su novela ejemplarizante Leonardo y Gertrudis, de 1781, como en otros escritos dirigidos a las madres de familia. En la novela se plasma la imagen de una madre campesina, virtuosa, caritativa, modesta, ordenada y creyente en Dios, quien forma una familia cristiana y civilizada, y salva a su esposo de las malas compañías y de sus debilidades morales; imagen que recurriría en los textos de formación de la familia en los dos siguientes siglos. Y la forma de salvarlo es por medio del amor, los consejos y la confesión: Gertrudis interroga a Leonardo cuando este llega a la casa sobre todo lo que ha hecho en el día. Y lo salva también a través de su encierro en el hogar en las horas de ocio, al no permitir la entrada de malas compañías:
¡Ay del desdichado si en su casa reúne malvados y corrompe con éstos al hombre honrado para que se pierda como ellos y para que olvide a Dios, a su mujer y a sus hijos, derrochando con ellos el producto de su trabajo que su mujer y sus hijos ansiosamente esperan! (Pestalozzi, 1916, p. 210)

Gertrudis, la madre y esposa, no solo gobierna moralmente el hogar, por medio de una aguda capacidad para valorar moralmente a las personas, actúa como consejera moral de los habitantes de la aldea y de las mujeres en cuanto al orden y la higiene de sus hogares, así como en las formas de disciplinar a sus hijos.

En uno de sus primeros escritos, Las horas vespertinas de un ermitaño, de 1780, Pestalozzi (1912) plantea que se debe dar mayor importancia a la formación en el hogar que en la escuela:

La educación de los hombres para esta o aque-

lla ocupación o para un rango social particular debe subordinarse a una educación que se dirige primordialmente a la pureza y la felicidad de la vida familiar. Por esta razón, el hogar debe ser el fundamento de cualquier esquema natural de educación. El hogar es la gran escuela del carácter y la ciudadanía. (p. 23)

La familia, en el discurso de Pestalozzi, se convierte en un modelo de formación para la escuela, en la que el maestro debe emular el amor materno y seguir el método de enseñanza que algunas madres utilizan de manera espontánea. Entre las ventajas de la formación familiar sobre la de la escuela está que en familia es más posible individualizar la formación:

Es su deber, en el círculo doméstico, hacer lo que
la instrucción escolar no tiene como lograr; darle a
cada niño individual ese grado de atención que en
la escuela es absorbido por la administración de la
totalidad; dejar que su corazón hable en casos en
que el corazón es el mejor juez; lograr por medio
del afecto lo que la autoridad nunca alcanzaría.
(Pestalozzi, 1912, p. 110)

En sus cartas sobre educación temprana escritas a J. P. Greaves, Pestalozzi (1827) subraya que la mujer es naturalmente amorosa por lo que "el deseo de hacer el bien ya está implantado en su corazón” (p. 4). Se trata de una sacralización del amor materno que se convierte en la verdad, el medio y el fin de la formación en la familia: "qué poder puede ser de mayor influjo, de mayor estímulo que el amor maternal, el cual es el poder más suave y a la vez el más intrépido de todo el sistema de la naturaleza" (Pestalozzi, 1827, p. 4). Es por medio de actos de bondad, en tanto manifestación del amor materno, que la madre produce 
las primeras impresiones en los ojos del infante; impresiones formativas que constituyen "la primera influencia de su conducta individual en la mente y el corazón del infante" (p. 45).

Se trata de un amor pensante (p. 5) que es tanto el fundamento de la formación moral como de la intelectual en la familia, convirtiéndose esta última, por vez primera en los textos que hemos examinado, en deber ya no del padre sino fundamentalmente de la madre en los primeros años de sus hijos. ${ }^{8}$ En un artículo anterior, de 1782, Pestalozzi se adentra en el mecanismo que hace posible el poderoso influjo de la madre a partir de las necesidades físicas y afectivas de los infantes:

Las necesidades sensoriales y corporales del niño conducen gradualmente a un desarrollo integral de las capacidades de su mente y su cuerpo. Si está hambriento, estira su brazo por pan y camina al lugar donde se guarda la leche. Aprende a ganarse el amor de aquellos de quienes necesita ayuda, busca escudriñar en el ojo de la madre lo que siente su corazón a favor o en contra de él. Conoce los tonos de su amor, de su alegría o ira porque te necesita y por esta necesidad debe ponerte atención. Por lo tanto, sus necesidades corporales son el fundamento del desarrollo de sus poderes; lo conducen, de manera simple y directa al doble fundamento de toda verdadera sabiduría humana y virtud: a la gratitud y al amor. (Pestalozzi, 1931, p. 36)

En cuanto a la formación moral, será tarea de la madre proteger la inocencia del niño en medio de un mundo corrupto:

En un mundo de inconstancia, de desconfianza, de incredulidad, ella debe ser asidua, para que la serena y amable seguridad de esa inocencia que ahora reposa en sus brazos, pueda un día crecer en una confianza inamovible en todo lo que es bueno aquí abajo y todo lo que es sagrado allá arriba. (p. 29)

El impedimento que vimos en textos anteriores para que la madre formara intelectualmente a sus hijos ha desaparecido, no porque las madres a las que se dirige Pestalozzi hayan sido escolarizadas, sino porque no considera que para ello deban ser instruidas por académicos y expertos, sino más bien seguir su propia experiencia y corazón. Las madres campesinas llevarían a la práctica aquello de lo cual los eruditos solo hablarían:

8 Este amor maternal que debía ser emulado por los maestros de escuela, sería la roca sobre la cual Pestalozzi construiría su pedagogía escolar. Véase Pestalozzi (1980).
[...] mientras los maestros de los hombres desde sus elevadas posiciones son tan indefinidos en sus versiones de lo que es correcto, con frecuencia las mujeres campesinas con total definición llevan a cabo aquello de lo que los primeros solo parlotean por medio de generalizaciones vacías. (p. 41)

Contra lo planteado o que se puede inferir de todos los textos anteriores y gran parte de los posteriores a Pestalozzi, este considera que los campesinos saben administrar bien sus hogares pues lo han aprendido de sus padres y por tanto no necesitarían ser formados sobre cómo hacerlo (p. 42).

En Pestalozzi, el origen y el fundamento de la formación moral y de la intelectual, está en los afectos que se generan en los niños a través del amor de la madre y en que estos sean protegidos e intensificados por los afectos de la madre: "Pero los afectos nunca han sido incentivados sino por otros afectos y la confianza nunca ha sido obtenida sino por confianza: el tono de la mente de la madre debe elevar el de su hijo" (p.58). Son los afectos los que llevan a sobreponerse al egoísmo animal (p. 70).

Pestalozzi propone un método de enseñanza intelectual para la madre en el hogar que sería el mismo que prescribiría para la reforma de las escuelas. Un método que es poco menos que mágico, ${ }^{9}$ que logra fundir amor y conocimiento, así como objeto y palabra y revelar la unidad del universo, en tanto la madre, quien ya ha establecido un vínculo de amor con su hijo, desde ese amor comienza a señalarle y a nombrar los objetos del mundo. Este sería el primer paso en la asociación que hace el niño entre lo moral y el conocimiento; proceso en el cual tanto la madre como el niño aprenden y que ya no depende de los conocimientos eruditos, pues la madre le abre al hijo el libro del mundo. Pero escuchemos en su voz el relato de Pestalozzi de este acto mágico:

Después de haberle enseñado en su seno a balbucear el nombre de Dios, le muestra ahora el Amor universal en el sol que se levanta, en el arroyo que ondea, en las fibras del árbol, en el esplendor de las flores, en las gotas del rocío; ella le muestra la inmensidad de Dios, en sí mismo, en los rayos de luz de sus ojos, en la flexión de sus articulaciones, en los sonidos de su voz [...]. Él abraza a Dios, al mundo y a su madre en un solo y mismo sentimiento [...]. Los labios que han sonreído tan a menudo desde el día de su nacimiento, la voz que el ha oído tantas veces desde el día que vio la luz del mundo anunciarle

9 En el sentido que le dieron a esta palabra Giordano Bruno, Pico della Mirandola y Marcelo Ficino; como una práctica que hace posible experimentar la unidad del individuo con los otros y con el cosmos. 
una alegría, esos labios y esa voz enseñan ahora a hablar; la mano que tantas veces ha estrechado contra el corazón que lo ama, le muestra ahora las imágenes de objetos cuyos nombres ya ha oído pronunciar a menudo. (Pestalozzi, 1980, p. 125)

Se trata de privilegiar los objetos y su impresión en los sentidos por encima de las palabras; los objetos son presentados a su hijo y luego:

[...] su origen debe ser explicado; sus partes deben ser descritas; y su relación con el todo establecida; se debe plantear su uso, sus efectos y consecuencias. Todo esto debe hacerse de una forma lo suficientemente clara y comprehensiva para que el niño pueda distinguir el objeto de otros objetos y poder dar cuenta de la distinción que lleva a cabo. (p. 123)

Pero la forma de explicar no es a través de lecciones, sino por medio de la conversación: "no se trata de hablarle mucho [...] sino de llevarlo a que se exprese sobre el tema; no agotar el tema sino de hacerle preguntas sobre el mismo; y dejar que encuentre las respuestas y luego corregirlas" (p. 252).

En Pestalozzi la madre se convierte en una formadora reflexiva y autorreflexiva que debe "pausar y examinarse a sí misma en cuanto a qué tanto puede esperar en tener éxito en inculcar aquello que no ha incorporado en su propia práctica" (p. 66). Uno de los asuntos centrales que debe examinar son las razones por las que los niños no se interesan por el aprendizaje, puesto que considera que en todas las ocasiones la falta de interés se debe a la forma de enseñanza de la madre y, en especial, al interés que ella demuestra en la formación de sus hijos:

Hay una extraordinaria acción recíproca entre el interés que la madre y el maestro tienen y lo que comunican a sus hijos y pupilos. Si no están con toda la mente presente en el asunto que enseñan; si no les preocupa si son comprendidos o no, si su forma de actuar les gusta o no, siempre alienará sus afectos, haciéndolos indiferentes a lo que dice. (p. 133)

\section{La responsabilidad de la madre y su moral como obediencia, autosacrificio y amor}

Hay una recurrencia en los textos desde el siglo XVI que en buena medida resuelve la paradoja de la configuración de la mujer como modelo moral y como formadora de la familia, y a la vez como subordinada al esposo: que la mujer es naturalmente (y debe ser) obediente. Y como es bien sabido, la moral cristiana es una moral de la obediencia (MacIntyre, 2000); es primordialmente porque se concebía que la mujer era mejor obedeciendo que el hombre, que se llegó a considerarla especialmente moral. Esta relación explícita entre ser obediente y formar/gobernar a la familia es formulada de la siguiente manera por el maestro e inspector de instrucción pública colombiano Milciades Chaves (1899):

La obediencia tiene además la ventaja de enseñar a gobernar. Así, una niña obediente a su madre sabrá más tarde gobernar su casa con acierto. Por medio de la obediencia en la familia es, pues, como se forman los buenos ciudadanos y las buenas amas de casa. (p. 24)

Todavía en 1942 en un Curso de preparación a la familia, de la Juventud Católica Femenina Colombiana, se ve esta relación entre ser obediente y buena formadora:

Con su ejemplo de sumisión al marido, con su arte de exquisita insinuación, sepa ella obtener naturalmente la flexibilidad de la voluntad del niño a la suya, apoderándose de su ánimo y preparándolo a la ejecución de sus órdenes, antes que la innata docilidad infantil forme en él el hábito de la rebelión. (Juventud Católica Femenina Colombiana, 1942, p. 53)

Otra virtud supuestamente femenina, cercana a la obediencia, la capacidad de autosacrificio, también es invocada para explicar sus dotes formativas; así, en el tratado traducido del francés de 1890 que circuló en Colombia: Educación de las madres de familia o la civilización del género humano por medio de las mujeres, se plantea lo siguiente:

En medio de tanto envilecimiento, ¿quién osará vivificar las almas con el santo amor de la verdad? Hay en el corazón de la mujer cierto espíritu de republicanismo que llama a la heroicidad y al olvido de sí propia y allí buscó su apoyo, allí encontró el poder. (Martin, 1890, p. 7)

A raíz de una transformación cuyo nacimiento habría que rastrear, pero que probablemente está vinculada al Romanticismo - y en el campo de la formación a Rousseau y Pestalozzi - la moral empieza a asociarse de manera decidida a la vida afectiva y a través de esta, a la mujer. Como dice Rousseau en 1762:

Si este fuera el lugar, trataría de mostrar cómo de los primeros impulsos del corazón se alzan las primeras voces de la conciencia; y cómo de los sentimientos de amor y de odio nacen las nociones de bien y mal. Haría ver que justicia y bondad no son solo palabras abstractas, puros seres morales formados por el entendimiento, sino verdaderas afecciones primitivas; que por la razón solo, independientemente de la conciencia, no puede establecerse ninguna ley natural; y que todo el derecho 
de la naturaleza no es más que una quimera si no está basado en una necesidad natural del corazón humano. ${ }^{10}$ (Rousseau, 2003, p. 248)

Pero no solo a la moral, con menos frecuencia, en los textos que hemos examinado, la afectividad de la mujer se asocia a una inteligencia práctica, como plantea Soledad Acosta (1845):

\begin{abstract}
[...] las mujeres generalmente hablando tienen una imaginación viva, un corazón sensible y una perspicacia fina y estas cualidades [...] las ponen en aptitud de dar un consejo útil y de descubrir a la primera ojeadas en los negocios, ventajas e inconvenientes que muchas veces se escapan a los hombres [...]. Hai casos en que las inspiraciones del corazón tienen mejor éxito que las meditaciones de la cabeza mejor organizada. (p. 36)
\end{abstract}

Lo anterior ayuda a entender esta nueva imagen de la mujer formadora: es por sus fuerzas emotivas y afectivas, más que por su intelecto que se considera que puede ser buena formadora; como lo señala Martin (1890): "Por medio del entendimiento educamos a las mujeres y deberíamos hacerlo por medio del corazón, porque las mujeres no saben sino lo que el corazón les enseña" (p. 57).

A la madre se le termina responsabilizando porque el hogar sea ordenado, limpio, virtuoso, acogedor, elegante, frugal y amoroso; así como por la moral de su esposo y la de sus hijos. Y una y otra vez se repite que siempre debe ser más virtuosa que el marido, en especial en su reacción a sus vicios: "No, la venganza más nombre que pueda tomarse de un marido infiel y perverso es oponer a sus malos procederes una conducta siempre inmaculada" (Acosta, 1845, p. 56). Enorme responsabilidad que se le recuerda con tonos severos y dramatúrgicos en los tratados de formación de la familia. Así en un texto inglés de 1815, Practical Hints to Young Females. On the Duties of a Wife, a Mother and a Mistress of a Family, ${ }^{11}$ leemos esta admonición a una recién casada:

La situación en que usted ha sido colocada es de enorme y vital importancia; apoye su dignidad por medio de su conducta y no deje que caiga en mala reputación y desdén. Las madres de quienes han decidido el destino de imperios fueron una vez jóvenes esposas, como usted lo es, y probablemente la felicidad o miseria de miles de individuos aún no nacidos dependieron de la conducta de ellas. (Taylor, 1815, p. 4)

10 Las cursivas son del texto citado.

11 Pistas prácticas para mujeres jóvenes sobre sus deberes como esposa, madre y señora de la familia.
Casi un siglo después, el pedagogo colombiano Martín Restrepo Mejía les advierte a las esposas que ellas son responsables tanto de la virtud de sus esposos como la de la sociedad: "Y es preciso que la mujer tenga muy en cuenta, desde niña, que de su virtud depende, en gran parte, la del hombre [...]. La mujer es el eje de la moralidad de las sociedades" (Restrepo, 1914, pp. 41-42). En la cartilla colombiana: Cartilla del hogar modelo obrero, de 1938, se hace responsable a la mujer, ya no del destino de imperios o de la sociedad, sino de hacer que su hogar sea vivible:

[...] el hombre tendrá que rendir cuentas a Dios de no haberlos procurado, en cuanto en su mano está, proporcionando los recursos necesarios para la vivienda; pero sobre la mujer pesa la enorme responsabilidad de que por su desaseo, abandono e ignorancia y pereza su hogar haya sido invivible y su marido e hijos víctimas de esta calamidad. (p. 13)

Y, claro está, también es responsable de aquello en que se conviertan sus hijos, como lo plantea con precisión estadística y fe en los efectos de la formación, el médico colombiano Eduardo Vasco Gutiérrez, en su tratado de 1934, El breviario de la madre:

Si usted ha sido precavida, metódica y abnegada, no tema. Desde este momento usted va a comenzar a modelar con sus propias manos un porvenir. Usted va a ser el artífice de un destino. Si usted lo dirige con constancia y con método, tiene noventa y cinco por ciento de probabilidades de hacer de su hijo lo que usted quiera. (Vasco, 1934, p. 22)

\section{Reflexiones finales}

Habría que considerar que, en gran medida, la nueva valoración moral de la mujer y la ampliación de su papel formador hacia los hombres, que hemos descrito, está vinculada a su rol como madre y esposa, y que probablemente dicha valoración y función formadora hacia los hombres no se hizo extensiva en buena parte del siglo XIX a las mujeres solteras, con o sin hijos. El hecho de estar inscritas en el régimen patriarcal propio de la institución matrimonial, las haría más dignas de confianza en términos morales, más inscritas en los cánones morales definidos por el gobierno eclesial de la vida: eso es, más obedientes, abnegadas y autosacrificadas. Aún la imagen ideal de Pestalozzi de la mujer formadora que logra fusionar el amor, la moral y el conocimiento, se inscribe en la misma racionalidad: lo puede hacer porque es madre; el intenso amor de la mujer, que es la clave del discurso de Pestalozzi, aparece por su instinto maternal. De la misma manera, y aquí entramos en una de las prácticas más interesantes que hemos 
descrito - la formación y gobierno mutuo entre esposo y esposa- su inscripción como formadora, aun del esposo, tiene que ver con su posición de sujeto como esposa. Quisiéramos argumentar que la esposa pudo llegar a concebirse como formadora de su esposo, no como mujer en sí, sino precisamente por ser esposa: por haber sido desde su matrimonio objeto de formación y gobierno por parte del esposo y de todo ese conjunto de expertos sobre la vida familiar que incluye, evidentemente, a los autores $\mathrm{y}$ autoras de los textos que hemos examinado. El régimen de formación/gobierno de la esposa sobre el esposo no constituye una fuga del dispositivo cristiano, patriarcal y civilizado de la familia: la esposa debe corregir las faltas del esposo para que este pueda ejercer mejor su soberanía sobre ella y los hijos. Tampoco son todas las mujeres las que entran a ser señaladas como salvadoras de la sociedad, sino solo las casadas o las viudas.

Vale la pena pensar más esta práctica de formación recíproca entre esposos y esposas. Por una parte, claramente densifica las prácticas de gobierno en la familia, a las que en la primera mitad del siglo xx hay que sumarles la emergente formación/gobierno de los hijos sobre sus padres, especialmente en los sectores populares, a quienes los maestros de las escuelas les daban orientaciones sobre cómo debían procurar que sus padres fuesen más higiénicos y civilizados. Emerge así la imagen, un tanto terrorífica, de un escenario en el cual, en discontinuidad en esto con la escuela, todos se forman entre sí (y por tanto se vigilan, se juzgan o valoran, se confiesan) de manera permanente y exhaustiva. Pero, por otra parte, también podríamos imaginar los efectos contrarios al arbitrario y soberano autoritarismo patriarcal que pudo tener la configuración de la familia como escenario primordialmente formativo, proyecto que atraviesa los textos que hemos analizado desde el siglo XVI hasta el pasado. Darles una racionalidad formativa a las conductas, en términos de lo que en los textos analizados se entiende como formación, ${ }^{12}$ les da un carácter estratégico, les da estabilidad al estar mediadas por el saber, lo cual, podría pensarse, establece mediaciones y regulaciones a la violencia que es inmanente a la soberanía casi sin límites que podía ejercer el hombre hacia su esposa e hijos. Y también podría pensarse que esta mediación del saber - posibilitada por la aculturación formativa de la familia- en las relaciones de poder enormemente asimétricas de la familia cristiana y civilizada, generó mayores condiciones de posibilidad para contracon-

12 Esta aclaración, que parece redundante, se debe a que hay acciones formativas que no son estratégicas. ductas exitosas por parte de las esposas y los hijos; por cuanto permitieron que las formas de gobernar/ formar se convirtieran en tema de reflexión, discusión y acuerdos.

\section{Referencias}

Acevedo de Gómez, J. (1869). Tratado sobre economía doméstica para el uso de las madres de familia, de las amas de casa y de las escuelas de niñas. Bogotá: Imprenta de Gaitán.

Acosta, S. (1845). Ensayo sobre los deberes de los casados para los ciudadanos de la Nueva Granada. Bogotá: Reimpreso por J. Ayarza.

Alberti, L. (2004) The Family in Renaissance Italy. Books one-four. Escrito entre 1434 y 1437. Long Grove (Il): Waveland Press.

Ariès, P. (1987). El niño y la vida familiar en el Antiguo Régimen. Madrid: Taurus.

Cartilla del hogar modelo obrero (1938). Publicada bajo los auspicios de la Alcaldía de Bogotá por un grupo de damas y por la Escuela de Servicio Social. Bogotá: Imprenta Municipal.

Conejos, P. (1920). Conferencias para señoras. Barcelona: Herederos de la Viuda Pla.

Chaves, M. (1899). Elementos de Educación ó sea moral, higiene, urbanidad y economía doméstica. Para uso de escuelas y familias. Bogotá: Imprenta de El Heraldo.

Dewey, J. (2004) Experiencia y educación. Edición y estudio introductorio de Javier Sáenz Obregón. Madrid: Biblioteca Nueva.

Donzelot, J. (1990). La policía de las familias. S.c.: Magazín de Troncos.

Elias, N. (1989). El proceso de la civilización. México: Fondo de Cultura Económica.

Fenelón, F. (1999). La educación de las niñas. Publicación en francés en 1688. Elaleph.com.

Foucault, M. (1975). El orden del discurso. Barcelona: Tusquets.

Foucault, M. (1977). Vigilar y castigar. El nacimiento de la prisión. México: Siglo XXI.

Foucault, M. (1978). La voluntad de saber. Historia de la sexualidad I. México: Siglo XxI.

Foucault, M. (1985). La arqueología del saber. México: Siglo XXI.

Foucault, M. (1988). El sujeto y el poder. Revista Mexicana de Sociología, 50(3), 3-20. 
Foucault, M. (1999a). Las técnicas de sí. En M. Foucault, Estética, ética y hermenéutica. Obras esenciales (vol. III). Barcelona: Paidós.

Foucault, M. (1999b). Subjetividad y verdad. En M. Foucault, Estética, ética y hermenéutica. Obras esenciales (vol. III). Barcelona: Paidós.

Foucault, M. (2000). Los anormales. Curso en el Collège de France 1974-1975. México: Fondo de Cultura Económica.

Foucault, M. (2006). Seguridad, territorio, población. Curso en el Collège de France 1977-1978. México: Fondo de Cultura Económica.

Juventud Católica Femenina Colombiana. (1942). Curso de preparación a la familia. Del Consejo superior de la juventud femenina católica italiana y traducido como iniciativa de la Juventud Católica Femenina Colombiana. (s.d.)

Locke, J. (2012). Pensamientos sobre la educación. Primera edición en 1693. Madrid: Akal.

MacIntyre, A. (2000). After virtue. A study in moral theory. 2a. ed. Londres: Duckworth, Second Edition.

Martin, A. (1890). Educación de las madres de familia o la civilización del género humano por medio de las mujeres. París: Garnier Hermanos.

Pestalozzi, J. (1827). Letters on Early Education Addressed to J.P. Greaves, Esq. By Pestalozzi. Londres: Sherwood, Gilbert and Piper.

Pestalozzi, J. (1912). Evening Hours of a Hermit. [Primera edición de 1780]. En J. A. Green (ed.), Pestalozzi's Educational Writings (pp. 15-32). Londres: Edward Arnold.

Pestalozzi, J. (1916). Leonardo y Gertrudis. Libro para el pueblo. Primera edición de 1781. Londres: Sherwood, Gilbert and Piper.

Pestalozzi, J. (1931). The Swiss News. En L.F. Anderson. Pestalozzi (pp. 35-47). Primera edición de 1782. Londres: McGraw Hill.

Pestalozzi, J. (1980). Como Gertrudis enseña a sus hijos. Primera edición de 1801. México: Porrúa.
Restrepo, M. (1914). Pedagogía doméstica. 3a. Madrid: F. Madriguera.

Rousseau, J. (2003). Emilio, o de la educación. Primera publicación en 1762. Madrid: Alianza.

Sáenz, J. (2014). Notas para una genealogía de las prácticas de sí. En J. Sáenz (ed.), Artes de vida, gobierno y contraconductas en las prácticas de sí (pp. 23-69). Bogotá: Centro de Estudios Sociales, Universidad Nacional de Colombia.

Sáenz, J. y Granada, C. (2013). El dispositivo de lo social como gobierno de los pobres en la primera mitad del siglo Xx en Colombia. En O. Restrepo (ed.), Ensamblando estado (pp. 219-252). Bogotá: Centro de Estudios Sociales, Universidad Nacional de Colombia, Colciencias.

Sombart, W. (2005). El burgués. Contribución a la historia espiritual del hombre económico moderno. Madrid: Alianza.

Taylor, A. (1815). Practical Hints to Young Females. On the Duties of a Wife, a Mother, and a Mistress of a Family. Londres: Taylor and Hessey.

Vasco, E. (1934). El breviario de la madre. Medellín: Imprenta Universidad.

Vierhaus, R. (2002). Formación (Bildung). Separata Educación y Pedagogía, xIv(33), 7-67. Medellín: Facultad de Educación, Universidad de Antioquia.

Vives, J. (1994). Los deberes del marido. Publicado en 1529. Valencia: Ajuntament de Valencia.

Vives, J. (1999). Instrucción de la mujer cristiana. Publicado en 1523. Madrid: Fundación Universitaria Española, Universidad Pontificia de Salamanca.

Zaldúa, M. (1891). Máximas y preceptos de moral, virtud y urbanidad para instrucción y provecho de mis adoradas hijas. Bogotá: Imprenta de Echeverría Hermanos.

Zuluaga, 0. (1987). Pedagogía e historia. Bogotá: Foro Nacional por Colombia. 